\title{
Viagem de longo curso: duzentos anos de historiografia francesa
}

\author{
A Travel of Long Time: Two Centuries of French Historiography
}

DELACROIX, Christian; DOSSE, François; GARCIA, Patrick. Correntes históricas na França: séculos XIX e XX. Traduzido por Roberto Ferreira Leal. Rio de Janeiro: Editora FGV; São Paulo: Editora Unesp, 2012. 478 p.

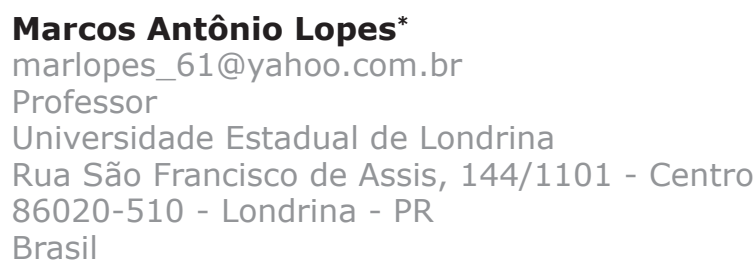

Keywords

Historical knowledge; History writing; French historiography. 
Nesta resenha, é apresentado um livro que impressiona pela agudeza das análises e pelo volume de informações colhidas ao longo de dois séculos inteiros de intensa atividade intelectual em torno dos itinerários percorridos pelo pensamento histórico e pela prática historiográfica dos franceses. A disposição dos autores para expor e discutir com largueza de vistas um elenco quase interminável de matérias cuidadosamente arranjadas e bem-encadeadas surpreende positivamente, sobretudo porque há poucas oscilações qualitativas quanto ao nível das análises. Os autores demonstram que leram com vagar praticamente tudo o que consideraram essencial na produção historiográfica de um longo período com citações recorrentes, volumosas e pertinentes dos textos de maior relevo. Apenas para se formar uma ideia do grau de detalhamento da obra, note-se que somente o sumário ocupa cinco bem preenchidas páginas no intuito de apresentar de modo transparente e organizado seis extensos capítulos compostos por unidades e subtítulos numerosos e bem discriminados, o que sem dúvida facilita a vida dos que se embrenham no cipoal das Correntes históricas na França.

Com carreiras em diferentes instituições francesas de ensino superior, Delacroix, Dosse e Garcia há anos compartilham um seminário no Instituto de História do Tempo Presente. No entanto, contrariamente ao que se verifica geralmente nas obras de vários autores, nada se diz acerca do processo de composição da obra, carência que não deixa de ser intrigante haja vista a organicidade do texto, bem como a unidade do estilo. De todo modo, fica

288 também evidente que muitas seções foram escritas individualmente, sobretudo pela forma como as análises dos próprios autores aparecem citadas. É particularmente notável em um livro de tão amplo escopo a capacidade reflexiva dos autores, que raramente perdem o senso de proporção. Apenas o sexto e último capítulo parece ressentir-se de ligeira hipertrofia, pela exposição excessiva de informações, que o desequilibra em face aos demais. De toda maneira, o livro cumpre com folga uma série de funções, dentre as quais destacaria o mérito de oferecer um amplo quadro das tendências e mutações da teoria e da prática historiadora em um país tão referencial para nós neste terreno como foi e ainda é a França. Por seus propósitos temáticos, a obra ainda vem prestar-se como instrumento de amplos recursos na atividade docente. Cada capítulo pode constituir-se em apoio precioso para aulas: pelo encadeamento lógico dos assuntos, pelo amplo recurso à documentação, pelas referências intertextuais e, ainda, pela contextualização das obras passadas em revista. De muito bom tom é o senso crítico observado pelos autores nas reflexões referentes a trabalhos mais atuais de colegas que com eles dividem o mesmo espaço profissional, uma tarefa crítica certamente nada confortável de se empreender.

Da singela introdução dedicada a demonstrar a natureza instável do conhecimento histórico, com as suas numerosas e sempre mutantes definições e concepções, a narrativa de Delacroix, Dosse e Garcia se consolida ao redor das representações que se constituíram em torno da Revolução Francesa. A Revolução foi o evento fundador do moderno sentido da história francesa, posto que desencadeou novidades sensíveis, abrindo caminho para a superação 
progressiva das crônicas dos feitos notáveis de personagens ilustres, bem como para a valorização das massas de anônimos como personagens centrais da história. Nesse ponto, os autores se revelam hábeis em demonstrar as vias pelas quais se processou o declínio de uma vocação moralizante da história e como a pesquisa do passado se tornou um ofício voltado a distinguir diferenças. Nos inícios do século XIX, essa nova forma de consciência histórica promoveria um rápido e quase completo apagamento de tradições então cultuadas, sobretudo as de natureza política, que continuaram a viver apenas na memória dos passadistas nostálgicos. Nesse âmbito, são apresentadas as contribuições originais de figuras modelares, a começar por Michelet. Nesse aspecto, o livro de Dosse e colegas promove contrastes bem-proporcionados dos historiadores centrais dessa primeira grande época ao passar em revista as contribuições de Quinet, Taine, Thierry, Guizot e Thiers. Nenhuma interpretação de relevo deixa de integrar o campo das análises sobre o sentido da história da França, incluídas as concepções liberais e as conservadoras em torno da Revolução Francesa, num tempo em que se empreenderam os primeiros balanços da grande crise. E os autores concluem pela impossibilidade de a primeira metade do século XIX ter propiciado uma História da França que fosse digna do nome. Tendo-se constituído em uma época de efervescência de novas concepções de história, a pesquisa histórica perdeu-se na diversidade das interpretações apaixonadas do romantismo.

O período das paixões políticas que marcou o nascimento da história contemporânea francesa ainda não arrefecera quando se abriu uma nova temporada para o conhecimento histórico. A nova tendência para se adotar procedimentos técnicos na organização da pesquisa tornar-se-ia pouco a pouco a corrente dominante na historiografia oitocentista. Os autores consideram que a tecnicidade representou um fator de avanço, mas, segundo eles, a tendência para as formalizações acabou por aviltar a natureza do conhecimento histórico, transformando-o em um procedimento padrão. A confiança excessiva na excelência de seus métodos como garantia de um conhecimento científico e, portanto, isento das contaminações da subjetividade, restringiu o campo de visão dos historiadores metódicos. No afã de revelar o passado por meio de procedimentos apropriados e eficazes para tal fim, os metódicos não perceberam que o gênero de história que lograram promover era não só acrítico quanto à sua própria natureza, como também havia-se afundado numa das formas mais evidentes de subjetividade: o patriotismo glorificador da França. Mas a oportunidade de experiências internacionais de que gozaram alguns historiadores franceses impulsionou os estudos históricos no país de Michelet. A análise comparativa que Victor Duruy empreendera no ano de 1867 e na qual avaliava as instituições universitárias francesas em face de suas congêneres alemãs ajudou a promover a criação da École Pratique des Hautes Études. Esse centro adaptou os elementos mais avançados da tradição alemã da pesquisa histórica para as condições requeridas à França e, com isso, ajudou a elevar o nível das pesquisas. A Alemanha tornou-se uma imagem a ser refletida na França em tudo o que dissesse respeito às inovações do ensino superior, inclusive da História. A fundação da Revue Historique, em 1876, e o papel que 
esse periódico desempenharia, junto com outros igualmente recém-criados, também assinalou uma conjuntura mais promissora para os estudos históricos. Um dos fundadores da Revue Historique, Gabriel Monod, lembrou-se de que, até então, os historiadores franceses não tiveram mestres nem formaram alunos. Em verdade, todos eram integrantes de uma geração de historiadores composta por autodidatas não inscritos em um ambiente profissional delimitado por regras conhecidas e compartilhadas, o que os levara a deixar transparecer tão intensamente a paixão política em seus livros. Mas os esforços de Ernest Lavisse e de alguns outros colaboradores vieram preencher essa lacuna importante. A partir de 1880 foram definidos os passos que conduziriam a uma mais evidente profissionalização da história. Nessa quadra, surgiram as condições para a emergência de uma corporação orientada por interesses comuns identificáveis, com normas específicas e uma grade curricular unificadora, junto com suas liturgias profissionais e os espaços próprios de reconhecimento. A multiplicação dos periódicos foi outro fator decisivo de avanço, pois eles constituíram e alargaram as redes de comunicação entre os especialistas.

Os dois nomes mais representativos do "momento metódico" foram Fustel de Coulanges e Hippolyte Taine. Em verdade, ambos foram os reais precursores do metodismo, destacando-se como os promotores da história como um campo identificado com a ciência. No entanto, segundo os autores de Correntes históricas na França, os princípios metodológicos fundados por Taine e Fustel foram ultrapassados por uma geração mais jovem. Com Langlois e Seignobos surgiu 290 o que se pode considerar como o "discurso do método histórico". Com efeito, o livro Introdução aos estudos históricos (1898) não apenas exibiria a confiança da história como campo disciplinar por meio de uma série bem constituída de procedimentos racionais, mas vinha instituir as regras de todas as operações que o historiador deveria empreender. Ainda que prestigiosa, já entre fins do século XIX e inícios do século XX a história metódica foi alvo de críticas intensas. Atacaram-na os que a tomavam como ingênua quanto à crença na possibilidade plena de análises objetivas do passado, incapacitada para a percepção de que aquilo que julgava método era em verdade um conjunto de escolhas particulares manchadas pelos próprios comprometimentos do historiador. Por essas e por outras limitações, a história entrou na linha de tiro de François Simiand, que nela identificou o culto à mitologia dos "três ídolos": a política, o indivíduo e a cronologia. As propostas para se compor um novo questionário para a história, com um roteiro não apenas mais perspicaz mas também mais complexo e ambicioso, passaram a vicejar nos primeiros anos do século $X X$.

A nova vocação crítica da história será um aspecto muito explorado pelos autores de Correntes históricas na França: séculos XIX e XX, sobretudo nos anos imediatamente posteriores à Primeira Guerra Mundial. Aliás, a Grande Guerra seria o centro das preocupações dos historiadores franceses nesta quadra. E as revoluções do conhecimento então em curso alertaram os especialistas acerca da necessidade de superação da história tradicional. As revelações da física quântica e a teoria da relatividade produziram impacto entre os historiadores. A concorrência de outros campos das ciências sociais colocaria a hegemonia 
da história em xeque. Geografia, psicologia e sociologia se apresentaram em um novo cenário intelectual. Os anos 1920 foram de crise intensa também pela contração do "mercado universitário" pós-guerra. As contratações contingenciadas e a própria carência de postos de trabalho entraram no cômputo dos maus tempos, crise ainda favorecida pela escassez de mentes criativas e inovadoras. Em meio ao marasmo, o "espírito de Estrasburgo" tomou os seus primeiros impulsos, materializando-se em 1929 com a criação da revista Annales. Detalhes sobre a criação do célebre periódico de "duas cabeças e quatro mãos" são analisados com vagar por Delacroix, Dosse e Garcia: o processo de idealização da revista, a definição de sua vocação, a composição editorial e a política de atração dos colaboradores, a grade temática dos números sucessivos, as dificuldades editoriais e as crises vividas pelos dois líderes, tudo passa por detalhada revisão. Sobretudo, é apontada a vocação cidadã da revista, pensada para ser um instrumento a serviço da análise crítica e em busca de soluções racionais para os problemas que afetavam as sociedades em crise. No entanto, segundo os autores, a mudança mais significativa foi de ordem prática, a partir dos trabalhos individuais de Febvre e Bloch. Em vez de definir a história pela ritualística de procedimentos complexos - a liturgia dos historiadores metódicos -, ambos a definiram pela série de seus novos conteúdos. O objeto e não o método doravante redefiniria uma história de nova face. Com Febvre e Bloch, a renovação da perspectiva histórica passou pela tomada de consciência de que a história só poderia existir se o historiador fosse capaz de formular problemas a partir de seu próprio aterramento histórico. Aqui estava em jogo o estabelecimento de uma história compreensiva que se opunha aos tribunais de moral e civismo. Doravante, a história seria um trabalho de imaginação construtiva. E os autores concluem o terceiro capítulo argumentando que a era Febvre-Bloch levou ao advento da fase de conquista da centralidade da história entre as ciências sociais, o que iria consolidar-se na era Braudel-Labrousse, correspondente aos anos 1950-1960.

Ainda que as análises nunca percam de vista o próprio chão histórico sobre o qual se movimentou a historiografia francesa desde os inícios do século XIX, a partir do fim da Segunda Guerra Mundial as abordagens contextuais ganham maior importância e volume. Em um mundo cada vez mais integrado e encurtado pelos novos interesses econômicos emergentes dos grandes Estados, as ciências sociais "explodiram" sob a demanda de necessidades prementes. As sociedades mais avançadas agora estavam carentes de técnicos e de peritos em setores vitais, e os cientistas sociais foram transformados em especialistas para o diagnóstico das transformações em curso. Na França, o Centre National de la Recherche Scientifique - que havia sido criado antes da Segunda Guerra -, desenvolveu-se e expandiu-se a partir dos anos 1950. Uma série de outros institutos foi criada. A estatística e a demografia tornaram-se vedetes e até certo ponto instrumentos domesticados dos poderes públicos. Esses movimentos são avaliados em suas minúcias, sendo louvado o papel político representado por Braudel, herdeiro direto de Febvre e personagem talhado para as necessidades do tempo. Com efeito, ele conseguiu erguer um verdadeiro império empresarial para a história. Com 
Braudel, verificou-se uma expansão crescente e rápida da história econômica e social, sobretudo por seu dinamismo como diretor do Centre de Recherches Historiques, braço historiográfico da Sexta Seção da École Pratique des Hautes Études. O papel desempenhado pela geração labroussinana é avaliado como um dos pontos historiográficos de mais alto relevo, comparável ou até superior à influência intelectual de Braudel. A emergência da história quantitativa e os debates acerca de seu método também são objeto de uma reflexão detida, assim como o advento de tendências como a nova onda da história política e a história das relações internacionais dos anos 1950. Também o movimento de renovação da história antiga na década de 1960 merece alguma atenção.

Os finais dos anos 1960 marcam outro momento de renovação da historiografia francesa. Rompe-se neste momento a relativa unidade das concepções mais amplas criadas pelos primeiros Annales. Como nunca antes, a história se aproximou do grande público, e os historiadores se tornaram celebridades por justos méritos e pela exposição nos meios de comunicação de massa. Esse foi o momento da Nova História, sustentado por um público ávido de repertórios apimentados por temas incomuns. A terceira geração da Escola de Annales alterou a natureza do discurso historiográfico. A morte ganhou terreno, assim como o nascimento, o batismo, o casamento, o vestuário, a infância, a comida e todo um corpo de assuntos relacionados à cultura material e aos imaginários coletivos. É o que se considera como um radical processo de "etnologização do discurso histórico", fortalecido ao longo dos anos 1970. A fragmentação dos objetos historiográficos

292 colocou em evidência um primeiro desdobramento da nova onda renovadora: a "inflação documental". Vestígios arqueológicos, imagens, tradições orais e todo gênero de registros ampliaram o campo de observação dos novos historiadores. E os "manifestos" lançados com o propósito de acentuar uma nova consciência historiográfica emergiram com vigor. Nessa quadra, nomes como Jacques Le Goff e Pierre Nora assumiram postos de vanguarda, com obras de conjunto da importância de Faire de I'histoire. No dizer de Delacroix, Dosse e Garcia, essa obra coletiva foi como "a carta constitucional da nova história". Abordagens como as de Emmanuel Le Roy Ladurie, com a sua "história sem os homens", que afasta o historiador de sua vocação de "especialista apenas em humanidade", também ganharam espaço entre as novidades dos anos 1960-1970. Em questão, a história do clima e dos imperceptíveis movimentos da natureza. A história das mentalidades vicejou como o terreno mais fértil no agora superexpandido território dos historiadores. Esse gênero historiográfico tinha como peculiaridade voltar as costas para as relações com o campo formal e organizado do pensamento para debruçar-se sobre as representações simbólicas das sociedades do passado. Fechou-se o espaço para as doutas racionalizações presentes nas doutrinas filosóficas que compunham a história das ideias. Os princípios fundamentadores desse gênero de pesquisa são examinados a partir das reflexões de historiadores considerados referenciais, como Ariès, Duby, Mandrou e Le Goff. A voga da história serial dos anos 1970, que levou ao momento da "embriaguez estatística", merece igualmente algumas páginas reveladoras, assim como as relações entre a pesquisa historiográfica e o ensino de história. 
O último capítulo é dedicado a retratar a fase de "anarquia epistemológica". Esse período corresponde aos anos 1980-1990 e se distingue por um volume concentrado de críticas ao paradigma Annales de história. As correntes que influíram nos debates daqueles anos são elencadas e avaliadas com vagar. A penetração de influências estrangeiras em solo francês marcou essa nova fase. As concepções marxistas de Thompson, a micro-história italiana e as tendências da história social inglesa tornaram-se referências importantes para se contrapor ao pós-estruturalismo e ao linguistic turn americano, então influentes. A própria dificuldade de renovação encontrada por gêneros consagrados, como a história das mentalidades e a história econômica, ajudou a fomentar a crise das identidades perdidas. A intensidade das críticas ao modelo dos Annales levou o grupo dirigente da revista a uma tomada de consciência que se expressaria pelo movimento conhecido como "virada crítica", responsável pela tentativa de uma ampla redefinição de perspectivas. Tal guinada seria, inclusive, objeto de um número especial da revista, o último do ano de 1989. No balanço geral, a distinção dos fatores intervenientes para a eclosão da crise. Segundo os autores de Correntes históricas na França: séculos $X I X$ e $X X$, a tendência um tanto irrefletida para o estabelecimento dos contatos da história com as demais ciências ajudaria a explicar a sua desestabilização, por tê-la feito perder as especificidades delineadoras de sua própria identidade. Em suma, o momento da "virada crítica" esteve marcado tanto pelo autoquestionamento quanto pela vontade de selecionar elementos capazes de promover a renovação da prática historiadora.

Decerto que muito ainda haveria a dizer deste livro caudaloso de três cabeças, pois o enredo continua a enumerar outros movimentos mais contemporâneos a vicejar pela historiografia francesa. Os desdobramentos de propostas como as da história do tempo presente e da história política merecem destaque em longas análises. Ênfase especial é conferida aos traumas provocados pela Segunda Guerra Mundial, que estabeleceu a Síndrome de Vichy e os ditos passados que nunca passam. E, no essencial, o livro se encerra ao redor dos debates acalorados que emergiram dos abalos da ocupação e do colaboracionismo, temas que proporcionam a superação das simples concepções retrospectivas por reencontrarem-se ainda em brasas no presente, evidenciando a próxima e conturbada relação entre os historiadores e os atores de um momento que não se apagou da memória. No cômputo geral de um giro de tão longo curso, resta a constatação de que, nos dias atuais, o inventivo pensamento histórico francês dá mostras de esgotamento. Depois da superação das convicções cientificistas e da longa presença da escola dos Annales, os pluralismos teóricos acabaram por realizar um trabalho de erosão. O traço mais evidente do anarquismo das teorias é o relativismo de perspectivas que, atualmente, muitos julgam de bom tom evidenciar. Mas, como alertam os autores, o risco das flexibilidades excessivas é o de alargar o campo de possibilidades a ponto de ameaçar a própria identidade de uma disciplina hoje tão carente de elos unificantes. Com efeito, a perda progressiva de seus núcleos vitalizadores, que a sustentaram como corpo dotado de um conjunto de pressupostos reconhecidos por seus praticantes, trouxe-a à beira do precipício em que agora se encontra. 